\title{
ENVÍO DE MENSAJES DE TEXTO PARA MEJORAR LA ADHERENCIA DE PACIENTES EN TARGA: ENSAYO ALEATORIZADO CONTROLADO
}

\author{
Iván Renato André Condori Lizárraga ${ }^{1, a}$, Luis Alberto Menacho Alvirio ${ }^{1, b, c}$, José Enrique Pérez-Lu ${ }^{1, b, d}$, \\ César Cárcamo Cavagnaro1,b,e
}

\begin{abstract}
RESUMEN
Objetivos. Evaluar la eficacia de una estrategia de envío de mensajes de texto (SMS) en la mejora de la asistencia a citas, adherencia al tratamiento y marcadores biológicos (carga viral y CD4) en pacientes continuadores con tratamiento antirretroviral de gran actividad (TARGA) que asistieron a destiempo a su última cita programada. Materiales y métodos. Se realizó un ensayo aleatorizado controlado implementado en Vía Libre, una organización no gubernamental (ONG) que brinda servicios a personas viviendo con el virus de la inmunodeficiencia humana $(\mathrm{VIH})$ en Lima. Se aleatorizaron 166 pacientes continuadores: 82 participantes recibieron SMS por seis meses y 84 participantes la atención estándar. Resultados. Los pacientes en el grupo de intervención, un 93,9\% fueron hombres y tenían una mediana de 5,1 años en TARGA; en cambio en el grupo control, un 94,1\% fueron hombres y una mediana de 5,3 años en TARGA. En el grupo de intervención, los pacientes asistieron con más frecuencia que aquellos en el grupo control a sus citas médicas programadas (RR=1,89; IC 95\%: 1,21-2,97) en los seis meses de intervención. Al comparar el nivel de carga viral y el nivel de CD4 no se encontraron diferencias ( $p=0,930$ y $p=0,905$, respectivamente). La adherencia al tratamiento medida por autorreporte fue mayor en el grupo de intervención $(p<0,001)$. Conclusiones. Los resultados en este estudio sugieren que el envío de SMS por seis meses puede mejorar la asistencia a citas y la adherencia al tratamiento en pacientes continuadores en TARGA.
\end{abstract}

Palabras clave: Cumplimiento y Adherencia al Tratamiento; VIH; Síndrome de Inmunodeficiencia Adquirida; Carga Viral; Recuento de Linfocito CD4 (fuente: DeCS BIREME).

\section{TEXT MESSAGING TO IMPROVE PATIENT ADHERENCE IN HAART: RANDOMIZED CONTROLLED TRIAL}

\begin{abstract}
Objectives. To assess the efficacy of a text messaging (SMS) strategy to improve appointment attendance, treatment adherence, and biological markers (viral load and CD4) in continuous patients with high activity antiretroviral therapy (HAART) who were late to their last scheduled appointment. Materials and Methods. A randomized controlled trial implemented in Via Libre, a non-governmental organization (NGO) that provides services to people living with human immunodeficiency virus (HIV) in Lima, Peru, was conducted, where 166 follow-up patients were randomized: 82 participants received SMS for six months and 84 participants received standard care. Results. Patients in the intervention group: $93.9 \%$ were men and had a median of 5.1 years in HAART; in the control group: $94.1 \%$ were men and a median of 5.3 years in HAART. In the intervention group, patients attended their scheduled medical appointments more frequently than those in the control group $(\mathrm{RR}=1.89,95 \% \mathrm{Cl} 1.21-2.97)$ during the six months of intervention. Comparing the viral load level and CD4 level, no differences were found ( $p=0.930$ and $p=0.905$, respectively). Adherence to treatment measured by self-report was higher in the intervention group $(p<0.001)$. Conclusions. The results of this study suggest that sending SMS for six months may improve appointment attendance and adherence to treatment in continuing patients on HAART.
\end{abstract}

Keywords: Treatment Adherence and Compliance; HIV; Acquired Immunodeficiency Syndrome; Viral Load; CD4 Lymphocyte Count (source: MeSH NLM).

Facultad de Salud Pública y Administración, Universidad Peruana Cayetano Heredia. Lima, Perú.

Biólogo, magíster en Informática Biomédica; ${ }^{\mathrm{b}}$ médico cirujano; ${ }^{\mathrm{c}}$ magíster en Salud Pública; ${ }^{\mathrm{d}}$ doctor en Salud Pública; ${ }^{\mathrm{e}}$ doctor en Epidemiología.

El presente estudio forma parte de la tesis: Condori I. Ensayo aleatorizado controlado del envío de mensajes de texto Para mejorar la asistencia a citas de los pacientes continuadores en TARGA [Tesis de Maestría]. Lima: Escuela de Posgrado, Universidad Peruana Cayetano Heredia; 2018. Recibido: 20/12/2018 Aprobado: 28/08/2019 En línea: 23/09/2019

Citar como: Condori Lizárraga IR, Menacho Alvirio LA, Pérez-Lu JE, Cárcamo Cavagnaro C. Envío de mensajes de texto para mejorar la adherencia de pacientes en TARGA: ensayo aleatorizado controlado. Rev Peru Med Exp Salud Publica. 2019;36(3):400-7. doi: http://dx.doi.org/10.17843/rpmesp.2019.363.4139. 


\section{INTRODUCCIÓN}

Uno de los Objetivos de Desarrollo Sostenible (ODS) por la Organización de Naciones Unidas es combatir la infección por el virus de la inmunodeficiencia humana $(\mathrm{VIH})$ y el Sida. A nivel global el acceso a terapia antiretroviral de gran actividad (TARGA) ha aumentado sostenidamente, evitando millones de muertes y contribuyendo a cumplir los ODS ${ }^{(1)}$.

Para evaluar los progresos ante la epidemia de $\mathrm{VIH} /$ sida se utiliza como principal indicador a la cascada de tratamiento. A nivel mundial, de las personas que viven con el $\mathrm{VIH}$, el $70 \%$ conocían su estado de $\mathrm{VIH}$, el $53 \%$ tenía acceso a la terapia antirretroviral y el $44 \%$ logró la supresión viral en 2016. Asimismo, del total de personas que viven con el VIH en Latinoamérica, el $80 \%$ conocían su estado de infección, el $50 \%$ tenía acceso a la terapia antirretroviral y el $46 \%$ logró la supresión viral (2). En Perú, en el 2014, de las personas que viven con el $\mathrm{VIH}$, el $64 \%$ conocían su estado de $\mathrm{VIH}$, el $46 \%$ tenía acceso a la terapia antirretroviral y el $36 \%$ logró la supresión viral ${ }^{(3)}$. Estas cifras muestran que en el Perú existen deficiencias en los tres niveles de la cascada; siendo lo más resaltante que sólo cuatro de cada diez personas que viven con $\mathrm{VIH}$ ha logrado la supresión viral.

La atención médica oportuna es necesaria para que las personas con $\mathrm{VIH}$ logren la supresión viral deseada. Debido a las mejoras en la atención médica y en los esquemas de tratamiento se ha podido lograr que el VIH se convierta en una enfermedad infecciosa crónica manejable ${ }^{(4)}$. Dos hechos muy importantes son que el TARGA debe ser tomado de por vida y que con niveles altos de adherencia se obtienen los mejores resultados en el sistema inmunológico del paciente, evitando la resistencia a los medicamentos $(5,6,7)$. Los principales indicadores de recuperación de la enfermedad son la supresión viral y el aumento en los niveles de CD4 ${ }^{(7)}$. Para lograrlo es crucial que los pacientes tomen sus medicamentos, los cuales son proporcionados en sus citas médicas.

En Perú, se estima que en 2016 la prevalencia de VIH en la población general fue de $0,3 \%$. En Lima, la prevalencia de $\mathrm{VIH}$ en hombres que tienen sexo con hombres fue mayor de $10 \%$ y en personas transgénero fue mayor de $20 \%$ (8); lo cual representa un gran problema de salud que no ha sido contrarrestado por las políticas actuales del país.

Diversas estrategias se han implementado para mejorar la adherencia al tratamiento y a las citas en los pacientes con $\mathrm{VIH}$. Un método innovador y económico es el uso de las tecnologías de la información y comunicación (TIC), especialmente el envío de mensajes de texto (SMS) a los pacientes. Algunos ensayos aleatorizados controlados han demostrado que esta intervención es beneficiosa para los pacientes con $\mathrm{VIH}^{(9,10,11)}$. Sin embargo, hay otros estudios donde la intervención no mejoró la adherencia de los pacientes ${ }^{(12,13)}$. Se requieren nuevas investigaciones, sobre todo en Latinoamérica, enfocadas en la mejora de la

\section{MENSAJES CLAVE}

Motivación para realizar el estudio. La adherencia al tratamiento es vital para reducir la morbilidad y mortalidad en pacientes con infección por VIH, sin embargo, muchos pacientes no cumplen su esquema de visitas.

Principales hallazgos. Este estudio encontró que el envío de SMS logró mejorar la asistencia a citas médicas, y la adherencia reportada al tratamiento.

Implicancias. El envío de mensajes de texto puede ser una alternativa para que los establecimientos de salud optimicen el cumplimiento de citas y adherencia al tratamiento de sus pacientes.

adherencia a medicamentos, al cumplimiento de citas, en el soporte emocional del paciente, entre otros.

El objetivo del estudio fue evaluar la eficacia de una estrategia con envío de SMS en la mejora de la asistencia a citas, adherencia al tratamiento y marcadores biológicos (carga viral y CD4) en pacientes continuadores con TARGA que asistieron a destiempo a su última cita programada.

\section{MATERIALES Y MÉTODOS}

\section{DISEÑO Y POBLACIÓN DE ESTUDIO}

Se realizó un ensayo aleatorizado controlado en Vía Libre, la cual es una ONG que ofrece atención en salud sexual, reproductiva y VIH en Lima, Perú. La consulta y despistaje de enfermedades de transmisión sexual tienen un costo, motivo por el cual suelen atenderse personas de un nivel socioeconómico medio, sin embargo, el tratamiento es gratuito como en todo el país. Sus pacientes, mayoritariamente hombres que tienen sexo con hombres $(\mathrm{HSH})$, mujeres trans, representan la epidemia concentrada que existe en el Perú ${ }^{(14)}$. En esta institución, durante la cita médica se entregan los medicamentos del TARGA. Para pacientes continuadores, las citas médicas son cada tres meses, $y$ las determinaciones de carga viral y CD4 se programan cada seis meses o cuando el médico lo considere necesario. En Vía Libre cuando los pacientes no asisten a sus citas, por protocolo, al cabo de unos meses se les llama para consultar si retomarán su terapia, pero en muchos casos las llamadas no son respondidas.

\section{CRITERIOS DE INCLUSIÓN Y MUESTRA}

Se consideraron como criterios de inclusión: ser mayor de 17 años, haber estado seis meses como mínimo recibiendo TARGA en Vía Libre, haber llegado a destiempo (un día después o más) a su última cita programada, tener teléfono celular con tarjeta SIM activo.

Mediante el programa Epi-Info ${ }^{\mathrm{TM}}$ versión 7.2.1 se determinó que un tamaño de muestra de 166 participantes (entre grupo control e intervención) era requerido para detectar un $20 \%$ de mejora en la asistencia a citas $(10,11)$, con un poder del $80 \%$ y un nivel de significancia del $5 \%$. 


\section{RECLUTAMIENTO Y ENROLAMIENTO}

Los pacientes continuadores de TARGA de la ONG Vía Libre que asistieron a destiempo a su cita (al menos un día después) fueron contactados por las enfermeras de la organización, y si cumplían los criterios de inclusión, fueron invitados a ser parte de la investigación desde el 29 de mayo de 2017 hasta llegar al tamaño de muestra el 29 de setiembre de 2017. Quienes accedieron voluntariamente a participar firmaron un consentimiento informado. Una vez reclutado el paciente, se procedió con la aleatorización, mediante bloques completos aleatorizados de tamaño cuatro, previamente desarrollado en un documento Excel, se colocaba el código del participante en el orden en que se les reclutaba, para asignarlos al grupo de intervención o al grupo control.

\section{SISTEMA DE ENVIOO DE SMS}

Se diseñó un sistema de envío de SMS para computadora con lenguaje de programación PHP que es compatible con Windows y Linux. Mediante un módem portátil y una tarjeta SIM de celular, este sistema permite el envío programado y la recepción de SMS a celulares. Posee un sistema de seguridad con contraseña y permite definir privilegios de usuario.

\section{VALIDACIÓN DE SMS}

La aceptación de los SMS en Vía Libre fue evaluada con tres grupos focales y 17 entrevistas a profundidad, en la mayoría de las entrevistas reportaron que los mensajes serían bien recibidos siempre y cuando sean discretos, no mencionen nada explícito referente a su condición o no sean demasiado frecuentes. El contenido de los SMS fue validado con cuatro grupos focales y entrevistas de validación, a cada uno de los participantes se le mostró una lista impresa de los SMS. Acto seguido el facilitador procedió a discutir con ellos acerca de cada SMS en función de la impresión en general, el fondo, la forma y la utilidad. En general los SMS con mensajes motivadores y generales fueron todos bien recibidos. Los participantes, jóvenes y adultos, mencionaron lo agradable que sería el recibir mensajes motivadores en sus celulares. Dichos mensajes deberían ser generales y no mencionar situaciones particulares, de modo que podrían ser para cualquier persona.

Los SMS, sobre recordatorio de citas, debían ser neutros, de modo que si alguien más leyera el teléfono no tendría modo de saber la razón de la cita. Los mensajes sobre la toma de medicamentos tuvieron discrepancias. Los participantes mayores, con familiares y amigos con conocimiento de su estado serológico, se mostraron bastante receptivos a mensajes con contenido directo, mientras que los más jóvenes, con diagnóstico reciente, se mostraron incómodos frente a mensajes con lenguaje explícito. Además, se sugirió no utilizar los términos medicamentos o «TARGA», sino un equivalente como vitaminas. Los tres mensajes de texto enviados con mayor frecuencia fueron: a) $¿$ Tomaste tus vitaminas? ¡Vamos con fuerza!, ¡Recuerda! Tienes una cita el (DD/MM/AA) a las (HH/MM), b) iTu eres lo mas importante!, La constancia es el secreto del éxito, y c) Toma tus vitaminas todos los dias. Veras los resultados. Los mensajes enviados se listan en el material suplementario.

\section{VARIABLES DE INTERÉS Y MEDICIÓN}

En tablas de Epi-Info y Excel se registraron los pacientes que recibían los SMS después de la aleatorización. Con historias clínicas y notas de enfermería se determinó la fecha en la que asistía el paciente a las citas médicas, esto se reportaba dicotómicamente (asistió a dos citas o asistió menos de dos citas), además se reportaron los días de retraso si el paciente llegaba tarde a su cita. Los niveles de carga viral y CD4 del paciente se obtenían de los reportes del Instituto Nacional de Salud (INS). La adherencia al tratamiento fue evaluada mediante la encuesta SMAQ (Cuestionario simplificado de adherencia a la medicación), la cual se encuentra en la Norma Técnica del Ministerio de Salud del Perú (15), clasificando a cada participante en varios niveles, desde poco adherente $(<30 \%$ de adherencia) hasta adherente óptimo (>95\%). Al finalizar el estudio los participantes completaron una encuesta de satisfacción, con siete preguntas, sobre la intervención. El nivel de satisfacción se categorizó usando los valores promedio en una escala de Likert para nivel bajo (1-2,33), medio $(2,33-$ $3,66)$ y alto de satisfacción $(3,66-5)$.

\section{INTERVENCIÓN}

El grupo control recibió sólo la atención estándar, la cual consistía en citas con el médico y con la enfermera, en las cuales también recibian su tratamiento, estas citas eran cada tres meses. Durante la intervención, las enfermeras no sabían a qué grupo pertenecía cada participante, sólo el investigador principal tenía acceso a esa información, ya que era necesario para poder buscar los datos clínicos de los participantes. Los participantes del grupo de intervención recibieron mensajes a los días de haber sido reclutados, el grupo control no recibió mensajes. El grupo de intervención recibió la atención estándar y se les envió dos mensajes recordatorios de cita, uno y tres días previos a la fecha de cada cita programada, además dos SMS por semana (cada miércoles y sábado) durante 24 semanas. El primer mensaje semanal fomentaba la adherencia. EI segundo mensaje semanal alternaba entre un mensaje motivacional y un mensaje informativo de salud en general. Los participantes recibieron mensajes que fueron diseñados para ser unidireccionales, es decir, no podían hacer preguntas o responder a los mensajes que recibieron; sin embargo, tuvieron la opción de mandar un SMS con la palabra «Finalizar» al número de envío si deseaban salir del estudio, esto pudieron hacerlo en cualquier momento de la intervención. El sistema de envío de SMS fue manejado totalmente por el investigador principal, quien, a manera de confirmación de envío, recibía copia de los mensajes enviados por el modem del estudio. 


\section{SEGUIMIENTO}

El seguimiento duró un periodo de seis meses, en el que tuvieron dos citas médicas que incluían la entrega de medicamentos. Con información de historias clínicas y registros de laboratorio se determinó si los participantes asistieron o no oportunamente a sus citas, su nivel de carga viral y su recuento de CD4.

En la segunda cita, es decir a los seis meses, completaron una encuesta de adherencia SMAQ, la cual se encuentra en la Norma Técnica del MINSA ${ }^{(15)}$. Los participantes que no asistieron a su cita programada tuvieron la posibilidad de completar la encuesta en una visita posterior, es decir cuando ellos llegaban a Vía Libre para recibir su medicamento y/o atenderse con un médico. Durante el análisis, a aquellos que no completaron la encuesta antes del fin del estudio se les asignó el nivel inferior de adherencia. En el caso del nivel de carga viral y CD4 basal, se registró el valor más reciente con relación a la fecha de reclutamiento (máximo seis meses antes de esta fecha). De la misma manera, para la visita de fin de seguimiento se consideró el valor más reciente con relación a la fecha de esa visita (máximo seis meses después de la fecha de reclutamiento). Sólo se incluyó resultados de carga viral y el recuento CD4 procesados por el INS.

\section{ANÁLISIS ESTADÍSTICO}

Para la descripción de las variables se usaron medianas, medias y rango intercuartílico (RIC) de acuerdo con la distribución de las variables. La medición de los resultados se realizó por un análisis de intención de tratar. Para la comparación de variables en la línea de base se usó la prueba de Mantel Haenszel, t de student y de chi cuadrado. Para evaluar el efecto de la intervención se calculó el riesgo relativo (RR) con su respectivo intervalo de confianza y valor de $\mathrm{p}$. En el caso del efecto de la intervención en el número de días de retraso a las citas programadas, se calculó la prueba de signo-rango de Wilcoxon. Todos los análisis fueron realizados con el programa Epi-Info versión 7.2.1.0.

\section{CONSIDERACIONES ÉTICAS}

El protocolo de este estudio fue evaluado y aprobado por los comités de ética de la Universidad Peruana Cayetano Heredia y de la Asociación Vía Libre. Se obtuvo consentimiento informado de todos los participantes. Los SMS enviados no mencionaron palabras que pudieran revelar información sensible sobre el participante, ni el nombre de la Asociación Vía Libre. Para referirse a los medicamentos antirretrovirales, los mensajes usaron la palabra «vitaminas». Los mensajes fueron diseñados como mensajes para una cita médica usual.

\section{RESULTADOS}

\section{FLUJO DE PACIENTES Y CARACTERÍSTICAS DE LA POBLACIÓN DE ESTUDIO}

Un total de 197 pacientes, que asistieron a destiempo a su última cita, de la Asociación Vía Libre fueron entrevistados para ser parte del estudio (Figura 1). Veintiocho de estos

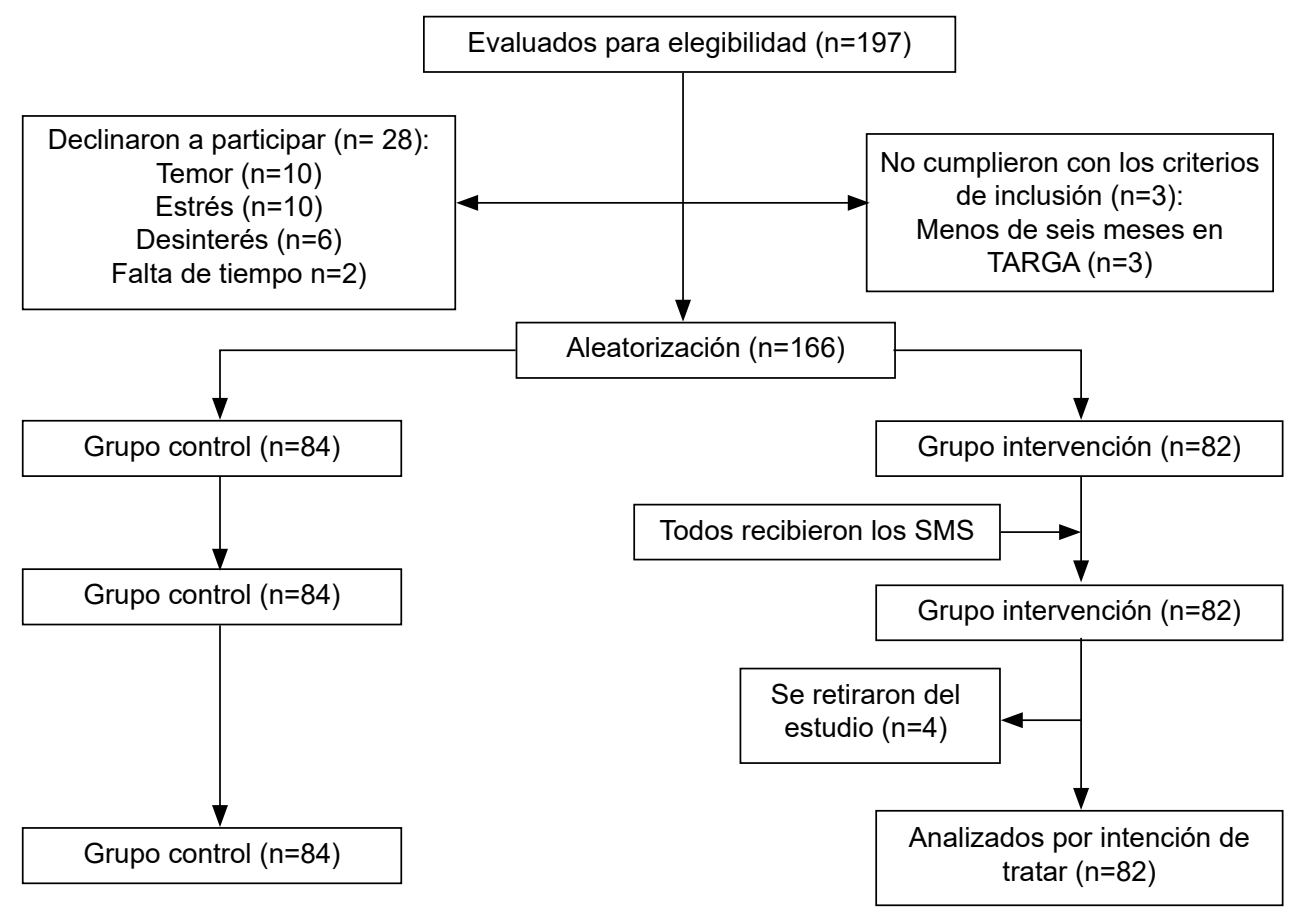

Figura 1. Diagrama de flujo CONSORT del estudio 
pacientes no aceptaron ser parte de esta investigación por temor a que otra persona pueda revisar los SMS o que estos mensajes puedan causarle estrés si es que otra persona revisaba su celular, otros motivos también para declinar esta invitación fueron: la falta de interés de recibir estos mensajes o reportaron no tener tiempo para este tipo de intervención. Tres pacientes que fueron entrevistados no cumplían con el criterio de inclusión: ser paciente de TARGA por un mínimo seis meses. Se enroló 166 participantes, 84 participantes fueron asignados al grupo control y 82 al grupo de intervención. Cuatro participantes del grupo de intervención se retiraron del estudio antes de completar los seis meses de seguimiento.

En la Tabla 1 observamos que no se encontraron diferencias entre grupos en la línea de base de los datos sociodemográficos ni las variables de estado de salud. Los participantes fueron mayoritariamente hombres, mayores de 35 años y solteros. Cerca de 50\% tenían estudios superiores y un porcentaje similar de participantes reportaron ser trabajadores dependientes. La mediana de los años en TARGA de los participantes fue un poco mayor de cinco años. De 75 participantes al iniciar el estudio, el promedio de carga viral en el grupo control fue de 20716 copias $/ \mathrm{ml} \mathrm{y}$ del grupo de intervención de 17058 copias/ml. El promedio de CD4 de 79 participantes al iniciar el estudio fue de 516 células $/ \mathrm{mm}^{3}$. En cuanto al autorreporte de adherencia al tratamiento, el $64,3 \%$ del grupo control y $58,5 \%$ del grupo de intervención reportaron tener una adherencia óptima.

\section{ASISTENCIA A CITAS, ADHERENCIA AL TRATAMIENTO YMARCADORES BIOLÓGICOS}

Al comparar la asistencia oportuna a citas en el grupo control y grupo de intervención (Tabla 2), se encontró que el grupo que recibió los SMS por seis meses asistió oportunamente a sus dos citas en un $89 \%$ más que el grupo control ( $R R=1,89$; IC 95\%: 1,21-2,97). Al comparar los niveles de carga viral y la diferencia de CD4 no se encontraron diferencias. La media de la carga viral del grupo control posterior a la intervención fue 28,2 copias/ $\mathrm{ml}$ y del grupo de intervención fue 26,3 copias $/ \mathrm{ml}, \mathrm{p}=0,930$. La diferencia promedio de CD4 del grupo control fue 14,3 (IC 95\%: -19,3 a 48,0) y del grupo de intervención fue 20,1 (IC 95\%: -67,7 a 107,8; p=0,905). Con respecto a la adherencia al tratamiento medida por autorreporte, se encontraron diferencias significativas $(p<0,001)$ entre ambos grupos.

Entre aquellos que no asistieron el día de su primera cita, la mediana del número de días de retraso en el grupo de intervención fue mayor que en el grupo control ( 28 vs. 14 días), aunque esta diferencia no fue estadísticamente significativa (Tabla 2). Para aquellos que no asistieron el día de su segunda cita, la mediana fue de más de 90 días en el grupo de intervención, y de 23 días en el grupo control, sin tener diferencias significativas.
Tabla 1. Características de los participantes incluidos en el estudio.

\begin{tabular}{|c|c|c|c|}
\hline Variable & $\begin{array}{c}\text { Control } \\
\text { n (\%) }\end{array}$ & $\begin{array}{c}\text { Intervención } \\
\text { n (\%) }\end{array}$ & $\begin{array}{l}\text { Valor } \\
\text { de p }\end{array}$ \\
\hline \multicolumn{4}{|l|}{ Género } \\
\hline Masculino & $79(94,1)$ & $77(93,9)$ & 0,969 \\
\hline Femenino & $5(5,6)$ & $5(6,1)$ & \\
\hline \multicolumn{4}{|l|}{ Grupo etario (años) } \\
\hline $18-24$ & $7(8,3)$ & $3(3,7)$ & 0,267 \\
\hline $25-35$ & $27(32,1)$ & $34(41,5)$ & \\
\hline 36 a más & $50(59,5)$ & $45(54,9)$ & \\
\hline \multicolumn{4}{|l|}{ Estado civil } \\
\hline $\begin{array}{l}\text { Soltero/ } \\
\text { Conviviente }\end{array}$ & $78(92,9)$ & $76(92,7)$ & 0,579 \\
\hline Casado & $6(7,1)$ & $5(6,1)$ & \\
\hline Viudo & 0 & $1(1,2)$ & \\
\hline \multicolumn{4}{|c|}{ Grado de instrucción } \\
\hline Primaria & $4(4,8)$ & $4(4,9)$ & 0,718 \\
\hline Secundaria & $39(46,4)$ & $33(40,2)$ & \\
\hline Superior & $41(48,4)$ & $45(54,9)$ & \\
\hline \multicolumn{4}{|l|}{ Ocupación } \\
\hline Estudiante & $14(16,7)$ & $11(13,4)$ & 0,931 \\
\hline Empleado & $44(52,4)$ & $43(52,4)$ & \\
\hline Independiente & $20(23,8)$ & $22(26,8)$ & \\
\hline Desocupado & $6(7,1)$ & $6(7,3)$ & \\
\hline $\begin{array}{l}\text { Años en TARGA, } \\
\text { mediana (RIC) }\end{array}$ & $5,3(2,50-7,50)$ & $5,1(2,30-8,00)$ & 0,192 \\
\hline $\begin{array}{l}\text { Carga viral basal } \\
\text { promedio* }\end{array}$ & 20716 & 17058 & 0,833 \\
\hline CD4 basal (RIC) ${ }^{*}$ & $477,0(316-635)$ & $555,3(369-733)$ & 0,579 \\
\hline \multicolumn{4}{|l|}{$\begin{array}{l}\text { Adherencia al } \\
\text { tratamiento }(\%)\end{array}$} \\
\hline $95-100$ & $54(64,3)$ & $48(58,5)$ & 0,676 \\
\hline $85-94$ & $17(20,2)$ & $22(26,8)$ & \\
\hline $65-84$ & $5(6,0)$ & $3(3,7)$ & \\
\hline $30-64$ & $0(0,0)$ & $0(0,0)$ & \\
\hline$<30$ & $8(9,5)$ & $9(11,08)$ & \\
\hline
\end{tabular}

RIC: rango intercuartil.

* Carga viral y CD4 disponibles para 75 y 79 participantes respectivamente.

\section{NIVEL DE SATISFACCIÓN}

Los participantes que recibieron SMS al finalizar el estudio llenaron una encuesta de nivel de satisfacción con la escala de Likert. Un total de 11 participantes no llenaron la encuesta porque no asistieron a su última cita programada. En la Tabla 3 se puede observar que el $72,0 \%$ de los 82 participantes que recibieron mensajes, reportaron un nivel de satisfacción alto a la intervención.

\section{DISCUSIÓN}

El presente estudio encontró que una intervención consistente en el envío de recordatorios e información sobre adherencia por medio de SMS logró incrementar la asistencia oportuna a citas médicas por parte de pacientes continuadores que reciben manejo de la infección por $\mathrm{VIH}$, 
Tabla 2. Efectos de la intervención en la asistencia a citas, nivel de carga viral, CD4 y adherencia al tratamiento.

\begin{tabular}{|c|c|c|c|c|}
\hline Variable & $\begin{array}{c}\text { Control } \\
\text { n (\%) }\end{array}$ & $\begin{array}{c}\text { Intervención } \\
\text { n (\%) }\end{array}$ & RR (IC 95\%) & $\begin{array}{l}\text { Valor } \\
\text { de } p\end{array}$ \\
\hline \multicolumn{5}{|l|}{ Citas asistidas oportunamente } \\
\hline Dos & $20(23,8)$ & $37(45,1)$ & $1,89(1,21,2,97)$ & 0,004 \\
\hline Menor a dos & $64(76,2)$ & $45(54,9)$ & & \\
\hline Días de retraso en la primera cita (RIC) & $14(7-39)$ & $28(10->90)$ & - & $0,064^{\dagger}$ \\
\hline Días de retraso en la segunda cita (RIC) & $23(8->90)$ & $>90(22->90)$ & - & $0,074^{\dagger}$ \\
\hline Carga viral promedio* & 28,2 & 26,3 & - & 0,930 \\
\hline Diferencia promedio de CD4* (IC 95\%) & $14,3(-19,3$ a 48,0$)$ & $20,1(-67,8$ a 107,9$)$ & - & 0,905 \\
\hline \multicolumn{5}{|l|}{ Adherencia al tratamiento } \\
\hline $95-100 \%$ & $39(46,4)$ & $60(73,2)$ & - & $<0,001$ \\
\hline $85-94 \%$ & $34(40,5)$ & $18(22,0)$ & & \\
\hline $65-84 \%$ & $7(8,3)$ & $0(0,0)$ & & \\
\hline $30-64 \%$ & $2(2,4)$ & $0(0,0)$ & & \\
\hline$<30 \%$ & $2(2,4)$ & $4(4,9)$ & & \\
\hline
\end{tabular}

IC 95: intervalo de confianza; RR: riesgo relativo; RIC: rango intercuartil.

* Carga viral y CD4 disponibles para 75 y 79 participantes respectivamente.

† Prueba de signo-rango de Wilcoxon

sin embargo, cuando se evaluó la relación entre el número de días de retraso a la cita con respecto a la intervención, no se encontraron diferencias en la primera y segunda cita. La intervención también logró mejorar la adherencia al tratamiento medido por autorreporte. La mayoría de los participantes en el grupo de intervención reportaron un nivel de satisfacción alto con la intervención.

Este sería el primer ensayo aleatorizado controlado del envío de SMS para mejorar la asistencia a citas en pacientes con $\mathrm{VIH}$ en Perú. Los hallazgos son consistentes con estudios realizados en otros países, enfocados en la asistencia a citas en pacientes con $\mathrm{VIH}{ }^{(9,11,16,17)}$ y con otras afecciones médicas ${ }^{(18,19)}$. A diferencia de otros estudios ${ }^{(9,10,11)}$ con resultados positivos, en esta investigación sólo se intervino con el envío de SMS y no llamadas telefónicas.

En general, las intervenciones con mensajes bidireccionales han obtenido mejores resultados en este tipo de estrategias en comparación con las intervenciones con mensajes unidireccionales ${ }^{(20,21)}$. En este estudio se enviaron mensajes unidireccionales los cuales tienen las siguientes ventajas: su implementación requiere menos recursos financieros; no necesitan de un personal altamente capacitado; y

Tabla 3. Nivel de Satisfacción medido por una escala de Likert $(n=82)$.

\begin{tabular}{lcc}
\hline Nivel de satisfacción & $\mathbf{n}$ & $\mathbf{\%}$ \\
\hline Alto & 59 & 72,0 \\
Neutro & 11 & 13,4 \\
Bajo & 1 & 1,2 \\
No llegó a su cita & 11 & 13,4 \\
\hline
\end{tabular}

Valores promedio en la escala de Likert para nivel bajo (1-2,33), medio $(2,33-3,66)$ y alto $(3,66-5)$ de satisfacción. representan una estrategia que puede acoplarse a otros servicios de soporte brindados en los centros de salud. Los mensajes bidireccionales, aunque brindan mayor interacción con el paciente, necesitan de un trabajador de salud que responda los mensajes en todo momento y esté capacitado para la amplia gama de posibles preguntas. El uso de SMS unidireccionales es una alternativa importante que puede ser considerada dependiendo del contexto y de los recursos disponibles.

Las variables secundarias como los marcadores biológicos (CD4 y carga viral) no se vieron afectadas por la intervención. Es probable que los seis meses de la intervención no hayan sido suficientes para medir un cambio significativo en los marcadores biológicos.

Por otra parte, la adherencia al tratamiento, medido por autorreporte, mejoró en el grupo de intervención producto del envío de SMS. Esto coincide con otras investigaciones con hallazgos positivos $(10,22,23)$. Sin embargo, en esta investigación sólo se utilizaron SMS y no otro tipo de estrategias como llamadas telefónicas o consejería complementaria a la atención estándar.

Diversos estudios han encontrado que tener un alto nivel de adherencia (mayor a 95\%) puede lograr la supresión viral deseada en los pacientes que viven con $\mathrm{VIH}{ }^{(24)}$. Que un paciente logre un nivel de adherencia mayor al $95 \%$ significa que debe tomar los medicamentos como mínimo, 86 de los 90 días. Si el paciente asiste a su cita cinco o más días después de lo programado, no estará tomando la medicación de esos días y tendrá una adherencia subóptima, disminuyendo sus posibilidades de lograr la supresión viral y aumentando la posibilidad de una resistencia a los medicamentos. La importancia en la salud pública de este tipo de investigaciones recae en 
identificar intervenciones que mejoren la asistencia a citas y la adherencia a terapia.

Este estudio tuvo varias limitaciones. En primer lugar, el sistema de envío de SMS podía permitirnos saber si el participante recibió el mensaje, pero no se podía comprobar si los participantes abrían o leían el contenido del mensaje. Segundo, la medición de la carga viral, CD4 y adherencia al tratamiento se realizó sólo en los participantes que asistieron a las citas, los cuáles pueden entenderse como los más responsables y por lo mismo, más adherentes al tratamiento; causando así una impresión de mejores resultados sólo en los participantes que asisten a las citas y no en la totalidad del tamaño muestral. Tercero, el seguimiento de los participantes fue de seis meses y se evaluó la asistencia a dos citas médicas, entonces los resultados están limitados a este periodo de tiempo y a estos dos controles médicos. Cuarto, esta intervención del envío de SMS ha tenido resultados positivos en la asistencia a dos citas médicas en este establecimiento de salud, sin embargo, puede que esta estrategia no sea tan efectiva en periodos muchos más largos de intervención. Quinto, no se midió la carga viral y CD4 a cada participante en la primera y última cita comprendido en la etapa de seguimiento; sino fue utilizada la información de cada paciente en el INS, donde se analizaron los valores más cercanos de carga viral y CD4 a estas citas. Finalmente, el autorreporte de adherencia está propenso al sesgo de recuerdo.

El estudio muestra que el envío de SMS durante seis meses mejoró la asistencia a citas y la adherencia al tratamiento en pacientes de TARGA. La intervención no afectó el número de días de retraso a las citas. Los marcadores biológicos como CD4 y carga viral no fueron afectados por esta intervención. Un alto porcentaje de los participantes que recibieron los SMS reportaron un nivel de satisfacción alto con la intervención.

Contribuciones de los autores: ICL, LMA, JPL y CCC participaron en la concepción del artículo, análisis, redacción y aprobación de la versión final. Además, ICL se encargó de la recolección de datos, confección de instrumentos y manual de procedimientos.

Fuentes de financiamiento: Fondecyt-Concytec

Conflictos de interés: Los autores declaran no tener conflicto de intereses.

Material suplementario: Disponible en la versión electrónica de la RPMESP.

\section{REFERENCIAS BIBLIOGRÁFICAS}

1. Organización de las Naciones Unidas. Objetivos de Desarrollo del Milenio [Internet]. ONU; 2015 [citado el 19 de diciembre de 2018]. Disponible en: http://www.un.org/es/millenniumgoals/ pdf/2015/mdg-report-2015_spanish.pdf

2. Crawford TN, Sanderson WT, Thornton A. Impact of poor retention in HIV medical care on time to viral load suppression. J Int Assoc Provid AIDS Care. 2014;13(3):242-9. doi: $10.1177 / 2325957413491431$.

3. The Joint United Nations Programme on HIV and AIDS. Ending AIDS Progress towards the 90-90-90 targets [Internet]. UNAIDS; 2017 [citado el 19 de julio de 2019]. Disponible en: https://www.unaids.org/sites/default/ files/media_asset/Global_AIDS update_2017_en.pdf

4. Crawford TN, Sanderson WT, Thornton A. Impact of poor retention in HIV medical care on time to viral load suppression. J Int Assoc Provid AIDS Care. 2014;13(3):242-9. doi: $10.1177 / 2325957413491431$

5. Safren SA, Mayer KH, Ou S-S, McCauley M, Grinsztejn B, Hosseinipour MC, et al. Adherence to Early Antiretroviral Therapy: Results From HPTN 052, a Phase III, Multinational Randomized
Trial of ART to Prevent HIV-1 Sexual Transmission in Serodiscordant Couples. J Acquir Immune Defic Syndr.2015;69(2):234-40. doi: 10.1097/ QAI.0000000000000593.

6. O'Neil CR, Palmer AK, Coulter S, O'Brien N, Shen A, Zhang W, et al. Factors associated with antiretroviral medication adherence among HIVpositive adults accessing highly active antiretroviral therapy (HAART) in British Columbia, Canada. J Int Assoc Physicians AIDS Care. 2012;11(2):13441. doi: 10.1177/1545109711423976.

7. Viswanathan S, Detels R, Mehta SH, Macatangay BJC, Kirk GD, Jacobson LP. Level of adherence and HIV RNA suppression in the current era of highly active antiretroviral therapy (HAART). AIDS Behav. 2015;19(4):601-11. doi: 10.1007/s10461-014-0927-4.

8. Jeremy YC, Kelika AK, Annick B, Patricia C, Alfonso SS, Jeffrey DK, Carlos FC. Peru's HIV care continuum among men who have sex with men and transgender women: opportunities to optimize treatment and prevention. Int J STD AIDS. 2016;27(12):103948. doi: $10.1177 / 0956462416645727$.

9. Bigna JJR, Noubiap JJN, Kouanfack C, Plottel CS, Koulla-Shiro S. Effect of mobile phone reminders on followup medical care of children exposed to or infected with HIV in Cameroon (MORE CARE): a multicentre, single-blind, factorial, randomised controlled trial. Lancet Infect Dis. 2014;14(7):600-8. doi: 10.1016/ S1473-3099(14)70741-8.

10. Abdulrahman SA, Rampal L, Ibrahim F, Radhakrishnan AP, Kadir Shahar H, Othman N. Mobile phone reminders and peer counseling improve adherence and treatment outcomes of patients on ART in Malaysia: A randomized clinical trial. PloS One. 2017;12(5): e0177698. doi: 10.1371/journal. pone.0177698.

11. Mugo PM, Wahome EW, Gichuru EN, Mwashigadi GM, Thiong'o AN, Prins $\mathrm{HAB}$, et al. Effect of Text Message, Phone Call, and In-Person Appointment Reminders on Uptake of Repeat HIV Testing among Outpatients Screened for Acute HIV Infection in Kenya: A Randomized Controlled Trial. PloS One. 2016;11(4):e0153612. doi: 10.1371/ journal.pone.0153612.

12. Junod Perron N, Dao MD, Righini NC, Humair J-P, Broers B, Narring F, et al. Textmessaging versus telephone reminders to reduce missed appointments in an academic primary care clinic: a randomized 
controlled trial. BMC Health Serv Res. 2013;13(1):125. doi: 10.1186/1472-696313-125.

13. Mbuagbaw L, Thabane L, OngoloZogo P, Lester RT, Mills EJ, Smieja M, et al. The Cameroon Mobile Phone SMS (CAMPS) trial: a randomized trial of text messaging versus usual care for adherence to antiretroviral therapy. PloS One. 2012;7(12):e46909. doi: 10.1371/journal.pone.0046909

14. Blas MM, Alva IE, Carcamo CP, Cabello R, Goodreau SM, Kimball AM, et al. Effect of an Online Video-Based Intervention to Increase HIV Testing in Men Who Have Sex with Men in Peru. PLoS One. 2010;5(5):e10448.56. doi: 10.1371/journal.pone.0010448.

15. Perú, Ministerio de Salud. Norma Técnica de Salud para la atención integral del adulto con infección por el virus de la inmunodeficiencia humana (VIH). NTS N 097 - MINSA/DGSP - V.02. Lima: MINSA; 2014.

16. Joseph Davey D, Nhavoto JA, Augusto O, Ponce W, Traca D, Nguimfack A, et al. SMSaúde: Evaluating Mobile Phone Text Reminders to Improve Retention in HIV Care for Patients on Antiretroviral Therapy in Mozambique. J Acquir
Immune Defic Syndr. 2016;73(2):e23-30. doi: 10.1097/QAI.0000000000001115.

17. Odeny TA, Bailey RC, Bukusi EA, Simoni JM, Tapia KA, Yuhas K, et al. Text messaging to improve attendance at post-operative clinic visits after adult male circumcision for HIV prevention: a randomized controlled trial. PloS One. 2012;7(9):e43832. doi: 10.1371/ journal.pone.0043832.

18. Vidal C, Garcia M, Benito L, Milà N, Binefa G, Moreno V. Use of text-message reminders to improve participation in a population-based breast cancer screening program. J Med Syst. 2014;38(9):118. doi: 10.1007/ s10916-014-0118-x.

19. Kerrison RS, Shukla H, Cunningham D, Oyebode O, Friedman E. Textmessage reminders increase uptake of routine breast screening appointments: a randomised controlled trial in a hard-to-reach population. $\mathrm{Br} \mathrm{J}$ Cancer. 2015;112(6):1005-10. doi: 10.1038/ bjc. 2015.36 .

20. Wald DS, Butt S, Bestwick JP. Oneway versus two-way text messaging on improving medication adherence: meta-analysis of randomized trials. Am J Med. 2015;128(10):1139.e1-5. doi: 10.4103/1119-3077.113451.
21. Mayer JE, Fontelo P. Meta-analysis on the effect of text message reminders for HIV-related compliance. AIDS Care. 2017;29(4):409-17. doi: 10.4103/11193077.113451 .

22. Maduka O, Tobin-West CI. Adherence counseling and reminder text messages improve uptake of antiretroviral therapy in a tertiary hospital in Nigeria. Niger J Clin Pract. 2013;16(3):302-8. doi: 10.4103/1119-3077.113451.

23. Lester RT, Ritvo P, Mills EJ, Kariri A, Karanja S, Chung MH, et al. Effects of a mobile phone short message service on antiretroviral treatment adherence in Kenya (WelTel Kenya1): a randomised trial. Lancet. 2010;376(9755):1838-45. doi: 10.1016/S0140-6736(10)61997-6.

24. Kobin AB, Sheth NU. Levels of Adherence Required for Virologic Suppression Among Newer Antiretroviral Medications. Ann Pharmacother. 2011;45(3):372-9. doi: 10.1345/aph.1P587

Correspondencia: Iván Condori.

Dirección: Av. Bolognesi 676, Sta. Anita, Lima, Perú.

Teléfono: 982353680

Email:ivan.condori.l@upch.pe 